\title{
Retrieval of the Eyjafjallajökull volcanic aerosol optical and microphysical properties from POLDER/PARASOL measurements
}

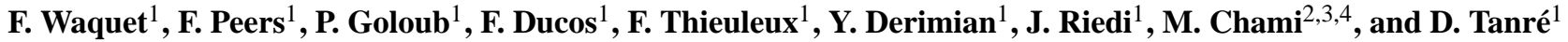 \\ ${ }^{1}$ Laboratoire d'Optique Atmosphérique, UMR8518, CNRS-INSU, Université Lille 1, Villeneuve d'Ascq, France \\ ${ }^{2}$ Université Pierre et Marie Curie, Laboratoire Océanographie de Villefranche, 06230, Villefranche sur Mer, France \\ ${ }^{3}$ CNRS, Laboratoire Océanographie de Villefranche, 06230, Villefranche sur Mer, France \\ ${ }^{4}$ Institut Universitaire de France, 103, boulevard Saint-Michel 75005 Paris, France
}

Correspondence to: F. Waquet (fabien.waquet@univ-lille1.fr)

Received: 29 December 2012 - Published in Atmos. Chem. Phys. Discuss.: 2 April 2013

Revised: 17 November 2013 - Accepted: 29 November 2013 - Published: 17 February 2014

\begin{abstract}
Total and polarized radiances provided by the Polarization and Directionality of Earth Reflectances (POLDER) satellite sensor are used to retrieve the microphysical and optical properties of the volcanic plume observed during the Eyjafjallajökull volcano eruption in 2010, over cloud-free and cloudy ocean scenes. We selected two plume conditions, fresh aerosols near the sources (three cases) and a downwind volcanic plume observed over the North Sea $30 \mathrm{~h}$ after its injection into the atmosphere (aged aerosols). In the near-source conditions, the aerosol properties depend on the distance to the plume. Within the near-source plume, aerosols are mainly non-spherical and in the coarse mode with an effective radius equal to 1.75 $( \pm 0.25) \mu \mathrm{m}$ and an Ångström exponent (AE) close to 0.0. Far from the plume, in addition to the coarse mode, there are particles retrieved in the accumulation mode, suggesting a mixture of sulfate aerosols and volcanic dust, resulting in an $\mathrm{AE}$ around 0.8 . The properties of the aerosols also depend on whether the plume is fresh or aged. For the downwind (aged) plume, if non-spherical coarse particles as well as some fine mode particles are retrieved, the $\mathrm{AE}$ is higher, around $\sim 0.4$. In addition, rather low values for the real part of the refractive index (RR) were retrieved for the fresh plume $(1.38<R R<1.48)$. Single scattering albedo (SSA) values ranging between 0.92 and 0.98 were retrieved over some parts of the near-source plume; despite the low accuracy of our retrievals, the derived SSA values suggest that the ash particles are rather absorbing. To consider the particle shape, a combination of spheroid models was used. Although the employed model enabled accurate modeling of
\end{abstract}

the POLDER signal in the case of non-spherical ash, our approach failed to model the signal over the optically thickest parts of the near-source plume. The most probable reason for this is the presence of ice crystals within the plume. For the aerosol above clouds (AAC) scenes, polarized measurements allowed the retrieval of the optical thickness (OT) and the AE of optically thin volcanic ash. We found that all the cloud parameters retrieved by passive sensors were biased due to the presence of the elevated volcanic plumes. Finally, thermal infrared measurements were used to identify the type of multilayer scene (cirrus clouds or volcanic dust above liquid clouds) and the retrieval method also provided the OT of thin cirrus layers above the clouds near Iceland.

\section{Introduction}

Aerosols are important contributors to Earth's climate change through their direct interactions with solar and telluric radiations, and indirect influence on clouds' microphysical properties and lifetime. Their global radiative forcing is negative and may partially counteract the warming effect of greenhouse gases. In spite of their significant impact on our climate, the direct and indirect aerosol effects remain very uncertain. Under such circumstances, it is important to unravel anthropogenic aerosols from natural ones, which is possible as long as the particles properties (especially the size distribution) are known and under the assumption that anthropogenic aerosol emissions (industrial, urban and biomass burning) are mainly characterized by fine mode particles, 
whereas natural aerosols (dust and sea salt) are characterized by the coarse mode. Volcanoes are also an important source of natural aerosols with both background adding from persistently active volcanoes and episodic perturbations from major explosive eruptions. Volcanic ash, injected into the atmosphere, scatter and absorb solar and infrared radiation. Volcanoes also emit precursor gases such as sulfur dioxide, which turn into secondary aerosols called sulfate aerosols. The other main sulfuric acid precursors that generate fine sulfate aerosols are sulfur dioxide from anthropogenic sources and dimethyl sulfide (DMS), which is mainly emitted by marine phytoplankton. As previously discussed, the distinction between anthropogenic and natural aerosols' contribution is important to understand the role of human activities in Earth's climate. Graf et al. (1998) estimated that the direct radiative effect of sulfate aerosol is about equally distributed between natural (i.e., volcanic) and anthropogenic aerosols. Volcanic sulfate aerosol effects are expected to be stronger since volcanic dusts are heavier and thus the rate at which they fall is faster. Although gravitational settling might be more rapid for volcanic ash than for sulfate aerosol, the relative impact of these species depends also on their relative optical depths, the particle microphysical properties (i.e., size, absorption and shape) and the likelihood of washout, which tends to affect sulfate aerosols more than dust. The height of injection of these particles into the atmosphere is also an important parameter. When volcanic aerosols reach the stratosphere, their lifetime is significantly increased because of the reduced efficiency of deposition processes. In that case, their impact on climate is much more significant, as was the case, for example, with Mount Pinatubo in 1991. Unlike high loading explosions, there are only a few studies about the impact of less explosive eruptions and when aerosols reach the troposphere (Gassó, 2008). The properties of ash particles (Muñoz et al., 2004) and the amount of sulfur ejected show a large variability from one eruption to another, which makes the estimate of their effects on climate difficult. During the Eyjafjallajökull volcano eruption in 2010, it was stressed that besides the radiative effect considerations, health hazards (heart and respiratory disease) and environmental effects (Mather et al., 2003), the monitoring of volcanic aerosols is also crucial for aviation safety.

Satellite remote sensing is already used for volcanic particles observation. Detection methods usually use infrared measurements because of their sensitivity to coarse mode particles. The French CNES-developed (Centre National d'Etudes Spatiales) Infrared Atmospheric Sounding Interferometer (IASI) aboard the EUMETSAT (European Organisation for the Exploitation of Meteorological Satellites) Metop satellites provides high spectral resolution infrared measurements, which have been efficient in quantifying sulfate gases and volcanic ash. The Ozone Monitoring Instrument (OMI) aboard the NASA Aura satellite, which provides measurements in the ultraviolet (UV) part of the spectrum, is also able to retrieve the sulfur dioxide concentra- tion. Currently, the visible part of the spectrum is poorly used in retrieving volcanic particles even though it could yield helpful information. The data provided by the Multiangle Imaging Spectro-Radiometer (MISR) instrument aboard the NASA Terra satellite were recently used to characterize volcanic aerosol particle properties in the visible part of the spectrum (Scollo et al., 2012; Kahn and Limbacher, 2012). The measurements provided by the French-developed instrument Polarization and Directionality of Earth Reflectances (POLDER) aboard the French PARASOL microsatellite have been applied to mineral dust and anthropogenic aerosols studies (Tanré et al., 2011). However, the instrument also allows to consider non-spherical particles such as those in volcanic aerosols (Muñoz et al., 2004) and, thanks to its polarization capabilities, it is very sensitive to fine mode aerosols, especially to their size and real refractive index. Another advantage of using polarized observations is that they provide the ability to detect and quantify aerosols transported above clouds. Volcanic aerosols have already been observed in cloudy scenes (Gassó, 2008). When they are located above clouds, aerosols can reduce the local planetary albedo and thus, have a warming effect. The impact mainly depends on the absorption properties of particles and on the albedo of the cloud underneath. Furthermore, aerosols above clouds induce biases in the retrieved cloud properties (Haywood et al., 2004).

The 2010 Icelandic eruption provides a great opportunity to study volcanic emission in the troposphere. This paper aims at studying the optical and microphysical properties of volcanic aerosols over the ocean (both clear-sky and cloudy-scenes) with POLDER on the one hand, and evaluating the contribution of polarization to study these particles on the other hand. The clear-sky analysis is focused on two case studies. The first one is dedicated to a transport case during the first eruption phase (16 April). The second one is related to the second eruption phase (7 May), both inside and near the volcanic plume. Lastly, the aerosols above clouds study looks at two cases (6 May and 8 May) near the source, during the second eruption phase (because of the cloud coverage). As a part of the constellation of satellites called A-train, POLDER acquired data in conjunction with multiple other passive and active sensors, such as NASA's Moderate Resolution Imaging Spectroradiometer (MODIS) aboard Terra and the Cloud-Aerosol Lidar with Orthogonal Polarization CALIOP) aboard the joint NASA and CNES environmental satellite CALIPSO (Cloud-Aerosol Lidar and Infrared Pathfinder Satellite Observations). POLDER's data will be supplemented with MODIS's information for clouds, and CALIOP layers heights and OMI's sulfur dioxide concentration are also used. 


\section{Methods}

\subsection{Clear-sky ocean scenes}

\subsubsection{Operational algorithm}

The quantities used to derive the aerosol and cloud properties from POLDER are the total and polarized normalized (unitless) radiances, as defined in Herman et al. (2005). POLDER measures the angular and spectral behavior of these radiances. The operational aerosol algorithm developed for POLDER uses the total and polarized radiances acquired at 0.67 and $0.87 \mu \mathrm{m}$ to derive several aerosol parameters based on a look-up table approach (LUT). This algorithm is used for a first qualitative detection of the volcanic plume over ocean cloud-free scenes. We recall that the algorithm considers two aerosol modes (i.e., a fine and a coarse mode) and that coarse mode particles consist of a mixture of spherical and non-spherical particles. The method uses an empirical model for the non-spherical coarse mode (Volten et al., 2001) and assumes non-absorbing particles in both modes. We refer to Herman et al. (2005) for more detail concerning the properties of fine and coarse mode spherical particles models used in the LUT and for the assumptions used for transfer radiative computations. The method mainly provides the aerosol optical thickness (AOT) and the Ångström exponent (defined using the 0.670 and $0.865 \mu \mathrm{m}$ wavelengths), which is a parameter indicative of the particle size distribution. A fraction of non-spherical particles within the coarse mode can also be retrieved when the geometrical conditions are favorable.

A cloud-screening algorithm is applied to the POLDER data. The cloud-screening is based on three tests: (1) a visible radiance threshold, (2) the detection of a cloud bow (i.e., a polarized radiance threshold), and (3) a criterion on the spatial variability of the visible radiance. Since we found that the third test is sometimes too stringent, we deactivated it for a small region over the volcanic plume observed on 6 May 2010 (see Fig. 9 for $58.5^{\circ}<$ latitude $<63^{\circ}$ and $-15.5^{\circ}<$ longitude $<-13^{\circ}$ ). We then strengthened the quality criterion used for the selection of pixels and eliminated those with an AOT larger than 2. We also noted that ash plume pixels were rejected by the first cloud-screening test on some occasions. The concerned pixels are associated with high radiance values that typically indicate cloud contamination. The paper mentions when we have deactivated this latter test.

\subsubsection{Research algorithm}

We use an alternative algorithm to further investigate the microphysical and optical properties of the volcanic plume particles observed by POLDER. The algorithm is an optimal estimation method (OEM), similar to the one described in Waquet et al. (2009b). With respect to the operational algo- rithm, we added the total and polarized radiances measured at $0.490 \mu \mathrm{m}$ by POLDER in the retrieval scheme, which allows us to increase the sensitivity of the algorithm to particle absorption and microphysics (Waquet et al., 2009b). Furthermore, a large range of scattering angles $\left(90-175^{\circ}\right)$ was sampled by POLDER for the two case studies over cloudfree ocean scenes, which allows sensitivity to particle shape (Herman et al., 2005). A combination of two lognormal size distribution functions is assumed as well as a mixture of spherical and non-spherical particles. We retrieve the column density particles number $\left(N, \mu \mathrm{m}^{-2}\right)$ and the two lognormal parameters (i.e., the mean radius and standard deviation) in both modes.

We consider spheroid models with various aspect ratios to compute the optical properties of the non-spherical particles (Mishchenko and Travis, 1994; Dubovik et al., 2006). The aspect ratio distribution for the non-spherical particle model is the one provided by Dubovik et al. (2006) from the analysis of the scattering matrix of mineral dust samples (Volten et al., 2001). The scattering matrices of both volcanic and mineral dust particles show similar features (Muñoz et al., 2004) and this particle model is therefore used to investigate the microphysical properties of volcanic dust particles. We only consider non-spherical particles for the coarse mode and we use the Mie theory to compute the optical and scattering properties of the fine mode particles. Therefore, we assume here that the fine mode particles are spherical, which is expected for sulfate aerosols. The main retrieved parameters are the aerosol optical thickness (AOT), the aerosol single scattering albedo (SSA), the fine mode effective radius $\left(r_{\text {eff }}\right)$, the fraction of spherical particles within the coarse mode (FS) and the complex refractive index $\left(m_{\mathrm{r}}-m_{i} i\right)$. We made assumptions for the complex refractive index in order to reduce the number of retrieval parameters. This complex refractive index is assumed to be equal in both modes and the real part of the refractive index is assumed to be spectrally invariant. We assume that the imaginary refractive index is $0.012 / 0.007$ times smaller at $670 \mathrm{~nm}$ than at $490 \mathrm{~nm}$. This ratio is based on the results from Derimian et al. (2012), which analyzed the properties of a volcanic plume observed on 17 April 2010 using Sun photometer measurements. This study also found a rather small spectral dependence for the absorption between $670 \mathrm{~nm}$ and $865 \mathrm{~nm}$. The imaginary part of the refractive index is therefore assumed constant between these two wavelengths in our algorithm. The vertical distribution of aerosol properties is assumed to follow a Gaussian function. The mean aerosol layer altitude $\left(Z_{\mathrm{a}}\right)$ is included in the retrieval scheme to prevent an erroneous assumption on the aerosol layer vertical position from causing a bias in our retrievals.

The OEM provides a retrieval error diagnostic. It takes into account the measurement sensitivity to the retrieved parameters, the measurement errors and any available a priori information. The measurement errors for the POLDER instrument are taken from Fougnie et al. (2007). The a priori 
Table 1. A priori knowledge of the aerosol parameters and associated uncertainties.

\begin{tabular}{llllllll}
\hline Parameters & AOT_f & AOT_c & $\begin{array}{l}r_{\text {eff_c }} \\
(\mu \mathrm{m})\end{array}$ & $\begin{array}{l}r_{\text {eff_f }} \\
(\mu \mathrm{m})\end{array}$ & $m_{\mathrm{r}}$ & $m_{i}$ & $\begin{array}{l}\text { FS } \\
(\%)\end{array}$ \\
\hline $\begin{array}{l}\text { A priori } \\
\text { knowledge }\end{array}$ & 0.05 & 0.4 & 1.97 & 0.225 & 1.47 & 0.005 & 50 \\
\end{tabular}

information and the associated uncertainties about the a priori information are reported in Table 1. The subscripts "f" and "c" respectively stand for the fine and coarse modes. The minimum and maximal values used for the size parameters and for the real part of the refractive index are typical values observed for fine and coarse mode aerosols (Dubovik et al., 2002). The coarse mode and fine mode AOT used as a starting point for the retrieval are respectively equal to 0.4 and 0.05 (at $865 \mathrm{~nm}$ ). These values were chosen based on the mean results obtained with the operational algorithm developed for POLDER. We use a value of 0.005 as a starting point for the retrieval of the imaginary part of the complex refractive index. This value is close to the one (0.004) prescribed by Schumann et al. (2011), which was derived from the joint analysis of ground-based lidar and airborne in situ measurements acquired for volcanic plumes observed on 16 and 17 April. For the imaginary refractive index we use an a priori of the maximal possible value of 0.02 , which relies on findings reported in Derimian et al. (2012). Because the a priori information for $Z_{\mathrm{a}}$ varies from one case to another, we mention it in the paper as necessary.

The polarized and total radiances are computed using the successive order of scattering (SOS) code (Lenoble et al., 2007). The code considers the scattering by molecules, the reflection of the Sun on the ocean (i.e., the glitter) and the ocean surface reflectance. The effects of foam and gas absorption on the POLDER measurements are corrected and we only keep the off-glint views for the retrievals. The ocean surface reflectance must be estimated at 0.67 and $0.49 \mu \mathrm{m}$ for an accurate retrieval. We use the MODIS ocean color products called "remote sensing reflectance" at $0.667 \mu \mathrm{m}$ and $0.488 \mu \mathrm{m}$ respectively to estimate the ocean surface reflectance in the 0.670 and $0.490 \mu \mathrm{m}$ POLDER bands. We use mean values computed over three months since this oceanic parameter shows quite a small temporal variability over the small oceanic regions investigated in this study (see box 1a in Fig. 1 and the box in Fig. 2) and during the considered period (spring 2010). We assume a maximal error of 0.005 for the surface reflectance given by MODIS and accounted for this error in our retrieval uncertainties. We assume a Lambertian reflectance model for the ocean surface reflectance, since the errors introduced by this assumption are small. We evaluated the effects of this assumption by using a radiative transfer code that allows to simulate the total and polarized radiances emerging from a coupled ocean-atmosphere system (Chami et al., 2001). The effects of the water-leaving radiance on the signal modeled at TOA can be safely ignored at $865 \mathrm{~nm}$ and are small at $670 \mathrm{~nm}$. Therefore, we only focused our analysis on the $490 \mathrm{~nm}$ spectral band. The directional (relative) errors for the total radiances at $490 \mathrm{~nm}$ vary between 0 and $4 \%$ for view angles $\left(\theta_{\mathrm{v}}\right)$ smaller than $40^{\circ}$, between 0 and $6 \%$ for $40^{\circ}<\theta_{\mathrm{v}}<60^{\circ}$ and between 0 and $7 \%$ for $\theta_{\mathrm{v}}>70^{\circ}$, depending on the relative azimuth angle. These calculations are valid for radiances computed at the top of the atmosphere, for Sun zenithal angles ranging between 30 and $60^{\circ}$, for a chlorophyll concentration smaller than $1 \mathrm{mg} \mathrm{m}^{-3}$ and for a pure molecular atmosphere. The effects of the water leaving polarized radiance over the open ocean are negligible at $0.670 \mu \mathrm{m}$ and $0.865 \mu \mathrm{m}$. We estimate the contribution of the water leaving polarized radiance to be inferior to $5 \times 10^{-4}$ at $0.490 \mu \mathrm{m}$ for our case studies (Harmel and Chami, 2008). We cannot account for these directional and polarized effects in our radiative transfer code and we therefore incorporated them into the OEM algorithm as an additional source of error.

\subsection{Aerosols above clouds}

A method that allows us to retrieve the AOT above clouds using polarized measurements was developed and evaluated for a case study relative to an elevated biomass burning aerosol layer transported above low-level clouds (Waquet et al., 2009a). This method is adapted for the AOT retrieval of fine mode particles, which are predominant in the case of anthropogenic aerosols such as biomass burning aerosols. We have recently developed a new method (Waquet et al., 2013) that allows to retrieve the AOT in the case of natural particles (i.e., mineral dust) transported above clouds using measurements acquired in the polarized cloud bow. The polarized cloud bow is a feature of liquid water cloud that corresponds to a highly directional and intense peak. When aerosols are overlying clouds, they attenuate the cloud bow. This attenuation is directly related to the AOT of the aerosol layer. In practice, the SOS code and the OEM are modified for the treatment of multilayer scenes. All available information in polarization (i.e., angular and spectral) is included in the OEM algorithm and the aerosol and cloud properties are simultaneously retrieved. This algorithm is used in a first step for the retrieval of a microphysical model of the volcanic plume particles. We describe in Sect. 3.2.2 the assumptions used to define the volcanic particles for the aerosol above clouds (AAC) scenes encountered in this paper. In a second step, we use this particle model to constrain the retrieval of 


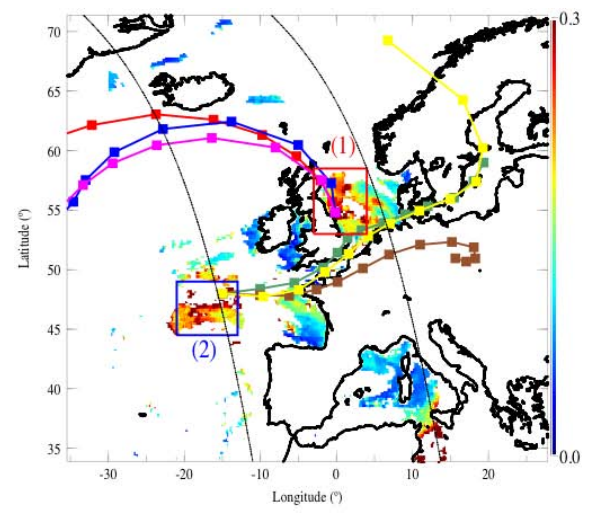

(a)

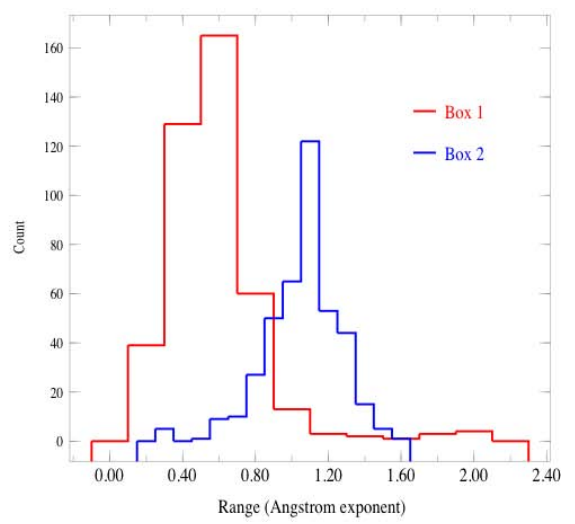

(b)

Fig. 1. Aerosol optical thickness (AOT) retrieved at $0.865 \mu \mathrm{m}$ by POLDER over ocean cloud-free pixels. The AOT values are relative to the PARASOL overpasses on 16 April 2010. For the area in panel (a), box 1, the air mass back trajectories calculated for altitudes equal to 0.5, 1.5 , and $3.5 \mathrm{~km}$ are in red, green, and magenta, respectively. For the area in (a), box 2, the back trajectories calculated for altitudes equal to $0.5,1.5$, and $3.5 \mathrm{~km}$ are in green, brown, and yellow, respectively. The coordinates of the ending point of the back trajectories in box 1 are $55^{\circ}$ latitude and $-0.15^{\circ}$ longitude. The coordinates of the ending point of the back trajectories in box 2 are $48^{\circ}$ latitude and $-15^{\circ}$ longitude The ending points time is 12:00 UTC and the squares denote calculations separated by $6 \mathrm{~h}$. The black thin lines are lidar CALIOP traces. Panel (b) depicts histograms of the Ångström exponent values retrieved for the areas in panel (a) boxes 1 and 2, respectively .

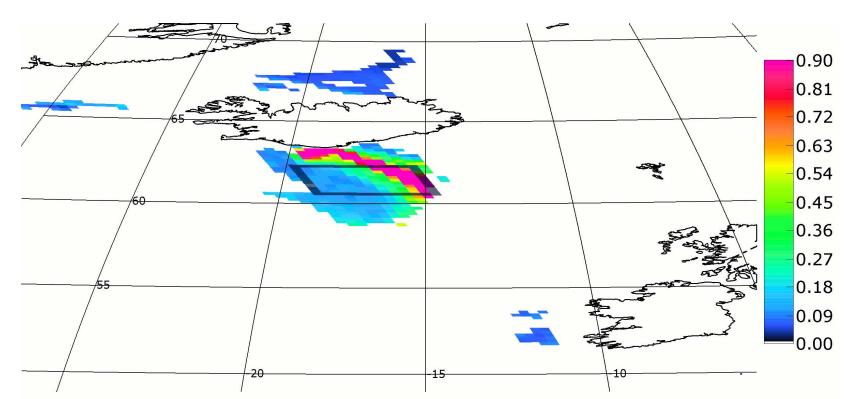

Fig. 2. Aerosol optical thickness retrieved at $0.865 \mu \mathrm{m}$ by POLDER over ocean cloud-free pixels south of Iceland. The AOT values are relative to the PARASOL overpass of 7 May 2010. The microphysical and optical properties of the aerosols observed for the area in the black box are depicted in detail in Fig. 4.

the AOT above clouds at a large scale using a simplified version of the algorithm. To reduce computation expense, a LUT approach is being used that considers 6 fine mode spherical models and an additional model for the volcanic particles. The variability of cloud properties within each POLDER pixel $(6 \mathrm{~km} \times 6 \mathrm{~km})$ is evaluated from MODIS retrievals at higher resolution $(1 \mathrm{~km} \times 1 \mathrm{~km}$ at nadir) and only homogeneous pixels are kept for the inversion. We restrict the retrievals to optically thick clouds (optical thickness $>3$.) since the polarized light reflected by the cloud (located below the aerosol layer) no longer depends on the cloud optical thickness because of a saturation effect. Our retrieval method is then restricted to AAC scenes with optically thick liquid cloud but has the advantage of being insensitive to the brightness of the underlying scene.

\section{Results}

\subsection{Cloud-free ocean scenes}

\subsubsection{Case studies}

The first case study is a transport of volcanic ash that occurred during the first eruptive phase. The eruption started on 14 April 2010 and injected a large amount of dust with $\mathrm{SO}_{2}$ in the troposphere. Figure 1a shows the AOT retrieved by POLDER over cloud-free ocean pixels using the operational algorithm on 16 April 2010. The area covers the northwestern part of Europe and the North Sea, as well as a large part of the northeastern Atlantic Ocean. AOTs larger than 0.3 are observed over the North Sea close to the coasts of England. Figure 1b shows the Angström exponent retrieved for this area. The particles are associated with small Ångström exponent values (a mean value around 0.5 ), which typically indicate a bimodal size distribution dominated by the coarse mode. The operational algorithm also detects a large amount of non-spherical particles within the coarse mode for this area, which confirms the presence of dust in the air. The origin of these particles was inferred from the back trajectories of the National Oceanic and Atmospheric Administration (NOAA) Hybrid Single-Particle Lagrangian Integrated Trajectory (HYSPLIT) model. The particles were transported over the course of 24 to $30 \mathrm{~h}$ from the south of Iceland over the Atlantic Ocean and then over the North Sea prior to their detection on 16 April close to England. The POLDER data were not available on 15 April but a volcanic plume was detected on 15 April in the south of Iceland by other space-borne radiometers (e.g., Kahn et al., 2012). The 


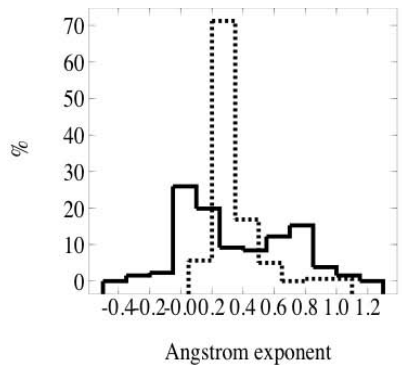

(a)

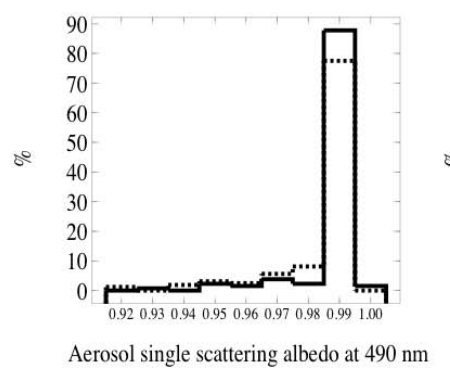

(d)

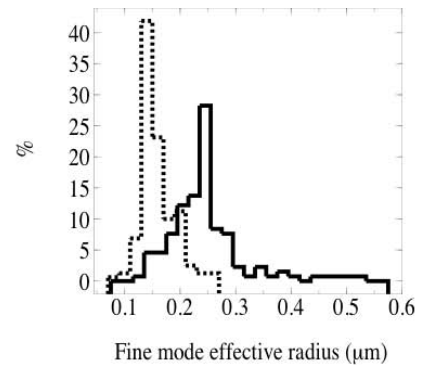

(b)

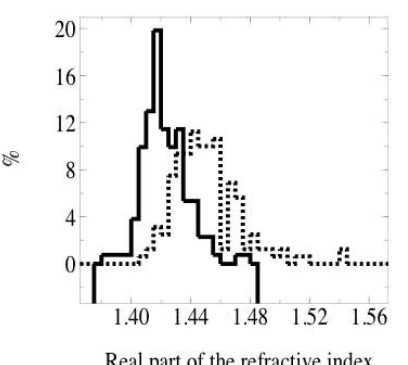

(e)

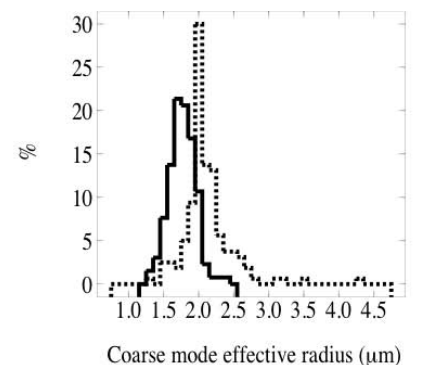

(c)

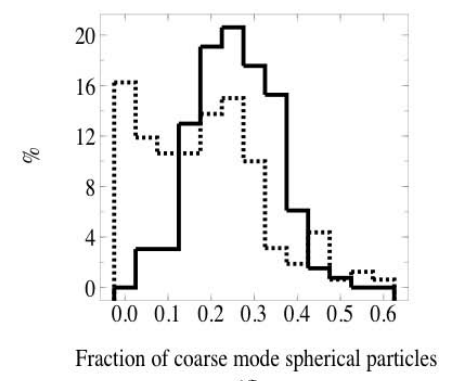

(f)

Fig. 3. Histograms of aerosol parameters retrieved for 16 April 2010 (dash lines) and for 7 May 2010 (solid lines). The area selected for 16 April 2010 is shown in Fig. 1a (red box). The area selected for 7 May 2010 is shown in Fig. 2 (black box).

back trajectories also suggest that the altitude of the volcanic plume progressively decreases during transport. This is in good agreement with the lidar CALIOP observations acquired on 16 April (see the CALIOP trace in Fig. 1). Figure 1a shows that the lidar did not overpass the thicker part of the volcanic plume, but intercepted the volcanic plume between latitude $54^{\circ}$ and $58^{\circ}$, where the plume was optically thinner. The CALIOP aerosol/cloud mask algorithm then detected aerosols located in the boundary layer between 0 and $1.5 \mathrm{~km}$. We therefore assumed a value of $0.75( \pm 0.75) \mathrm{km}$ as a first guess for the mean altitude of the aerosol layer $\left(Z_{\mathrm{a}}\right)$ for this case. The column amount of $\mathrm{SO}_{2}$ retrieved by the OMI instrument (middle troposphere product) over the plume on 16 April appears to be small ( $<0.5$ Dobson units, DU) and is generally below the uncertainty threshold associated with this parameter (0.3 DU).

A second plume of aerosols can be observed over the Atlantic Ocean between latitudes $50^{\circ}$ and $55^{\circ}$. This plume is also associated with AOTs of about 0.3 at $0.865 \mu \mathrm{m}$. However, the Ångström exponent values are around 1.2 (see Fig. 1b) and the standard operational algorithm only detects spherical particles. This plume is located in the boundary layer according to CALIOP observations.

The back trajectories computed for this event indicate a continental origin (see Fig. 1a) and suggest a transport that occurred in the lower part of the atmosphere $(<1 \mathrm{~km})$. This information altogether suggests a transport of boundary layer pollutant aerosols that originated from the northeastern part of Europe. Large AOT values are also observed in the AOT map over the Mediterranean Sea, which correspond to min- eral dust particles. These two events are not related to the eruption and we therefore did not investigate these events in detail.

Figure 2 shows AOT retrieved by PARASOL on 7 May near Iceland. POLDER detected a volcanic plume associated with large AOT values, as large as 2.4 at $0.865 \mu \mathrm{m}$ over the core of the plume. We deactivated the POLDER cloud mask algorithm over the core of the plume since this part was initially classified as cloud contaminated. The operational algorithm detects a large amount of non-spherical particles in the coarse mode for this event. The column amount of $\mathrm{SO}_{2}$ retrieved by OMI is significant and shows values larger than 3 DU. We assumed a value of $4.5( \pm 1.0) \mathrm{km}$ as a first guess for the mean altitude of the aerosol layer $\left(Z_{\mathrm{a}}\right)$ for this case, which is suitable for this plume (Kahn et al., 2012).

\subsubsection{Characterization of volcanic particle properties}

Figure 3 shows histograms of the aerosol properties retrieved on 16 April and 7 May, referred to later as downwind and near-source cases or plumes, respectively. We selected two small regions for each plume, where we applied the research algorithm (see Fig. 1a, box 1 and the box in Fig. 2).

The histogram for the Ångström exponent is roughly divided into two parts centered at 0.0 and 0.7 , respectively, for the near-source case. This indicates two different types of particle size distribution. The fine mode effective radius retrieved for this case varies between $0.2 \mu \mathrm{m}$ and $0.3 \mu \mathrm{m}$. The coarse mode effective radius is around $1.75 \mu \mathrm{m}$. The size parameters retrieved for the downwind case show less 


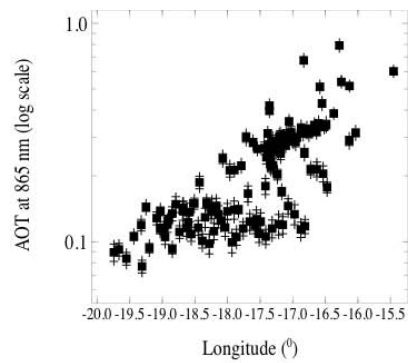

(a)

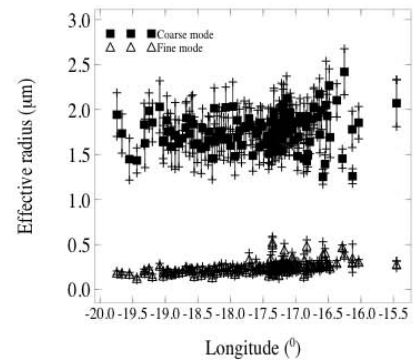

(d)

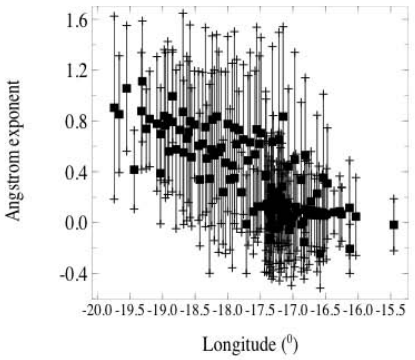

(b)

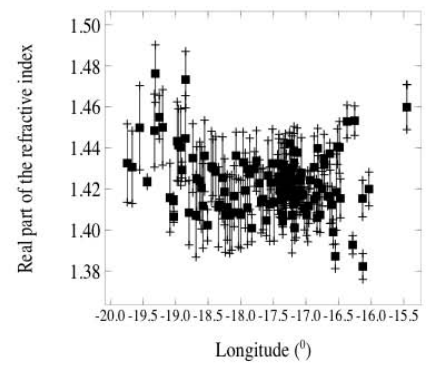

(e)

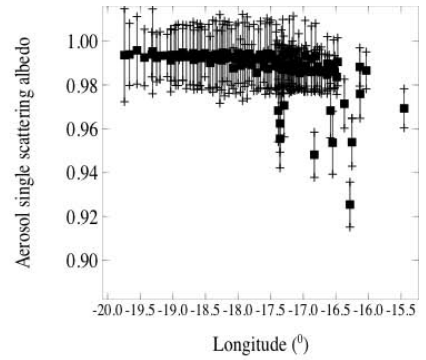

(c)

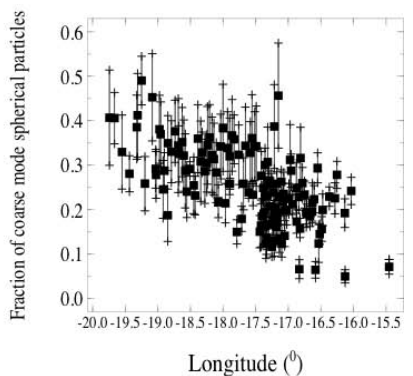

(f)

Fig. 4. Aerosol parameters (squares or triangles) and associated uncertainties (lines with crosses) retrieved on 7 May 2010 , shown in function of longitude. The longitude increases as the distance to the volcanic plume decreases. The selected area is shown in Fig. 2 (black box).

variability. The Ångström exponent is around 0.4. The uncertainty is about \pm 0.35 on average for this parameter. The fine mode and coarse mode effective radii are respectively smaller and larger for the downwind case and are respectively around $0.16 \mu \mathrm{m}( \pm 0.015)$ and $2.0 \mu \mathrm{m}( \pm 0.5)$. The uncertainty associated with the coarse mode effective radius is quite large for the downwind case and the differences observed between the two plumes for this parameter are therefore not significant.

The imaginary part of the complex refractive index generally decreases from 0.005 (starting point of the retrieval) to values slightly smaller than 0.001 . This leads to a high SSA value of about 0.99 at $0.490 \mu \mathrm{m}$ for most observations, with some exceptions noted, for instance, over the core of the plume on 7 April, as discussed later, and for a few pixels observed for the downwind case. A significant fraction of coarse spherical particles is observed near the source (around $30 \%$ on average) whereas less coarse spherical particles were detected for the downwind plume $(10 \%$ on average). Volcanic dusts are mainly made of silicates and typically exhibit a large value for the real part of the refractive index in the visible part of the spectrum. For instance, the real refractive index varies from 1.48 to 1.56 for silicate glass, with $\mathrm{SiO}_{2}$ concentration inversely varying between $55 \%$ and $78 \%$ (Williams et al., 1982). The real refractive index values retrieved for the downwind plume are too uncertain to draw conclusions. For the near source case, the retrieved real refractive index varies between 1.39 and 1.45 for most of the pixels, which requires further analysis.

Figure 4 shows the parameters retrieved for the nearsource case as a function of the longitude. This allows us to observe the variability in the aerosol properties as a function of the distance to the plume. The point of longitude $-20^{\circ}$ in Fig. 4 is located at about $200 \mathrm{~km}$ from the thickest part of the volcanic plume. The observed plume also reached the longitudes up to about $-17.5^{\circ}$. The retrievals made over the thickest parts of the plume were not reported in Fig. 4, for the reasons explained below. Note that the retrievals were performed at the finest spatial resolution of POLDER $\left(6 \times 6 \mathrm{~km}^{2}\right)$ in the vicinity of the volcanic plume and that a "log-scale" is used for the AOT shown in Fig. 4a. The AOTs retrieved with the research algorithm are generally in a good agreement with those retrieved with the operational algorithm. However, we noted large differences between the two methods over the volcanic plume. The other optical and microphysical parameters are associated with uncertainties larger than the ones associated with the AOT. Nevertheless, significant tendencies can be observed for all the parameters.

We first describe the observations made far away from the plume (for longitudes west of $-19^{\circ}$ ). The algorithm retrieves an Ångström exponent of about 0.8 , which indicates a bimodal size distribution. The contribution of the fine mode to the total aerosol optical thickness is about $35 \%$ at $865 \mathrm{~nm}$ (not shown). The aerosols consist of a mixture of fine (spherical) particles with spherical and non-spherical coarse particles. The fraction of spherical particles within the coarse is about $40 \%$. The retrieved fine mode effective radius is around $0.20 \mu \mathrm{m}$. The retrieved real part of the refractive index is around 1.43. This combination of particles does not show absorption as long as we are far enough from the core of the plume. The aerosol single scattering albedo at $490 \mathrm{~nm}$ is then 
typically high $(\sim 0.99$ at $0.490 \mu \mathrm{m})$ and does not show much spectral variability.

Figure $1 \mathrm{~b}$ shows that the Angström exponent values progressively decrease from about 0.8 to 0.0 as the distance from the plume decreases. The contribution of the fine mode to the total AOT decreases from $35 \%$ to $10 \%$ at $865 \mathrm{~nm}$ (not shown). The fraction of spherical particles also decreases as the distance from the plume decreases. Volcanic aerosol observed near the source often contains a combination of coarse mode particles dominated by silicate of various shapes, sizes and compositions, mixed with fine mode particles made of sulfuric acid or ammonium sulfate. These properties were confirmed by airborne in situ measurements performed near the source of this eruption (Schumann et al., 2011). Our results indicate that we have indeed a mixture of non-spherical coarse particles (i.e., volcanic dust) mixed with fine mode particles that are likely to be sulfate aerosols. The coarse mode effective radius remains rather constant, which suggests that the same type of dust is observed for the selected field of observations. Figure 4e shows that the real part of the refractive index is rather low over the entire transect $(\sim 1.42$ on average), which is quite surprising for volcanic dust. The fine mode effective radius progressively increases as the distance to the volcanic plume decreases and becomes more variable over the plume.

The properties observed over the plume (for longitudes $>-17.5^{\circ}$ ) are therefore quite different from the ones retrieved far away from the plume. The size distribution is dominated by the coarse mode and the particles are mainly non-spherical (less than $25 \%$ of spherical particles, on average). The SSA is lower, indicating the presence of absorbing materials. The lowest values retrieved for the SSA are of $0.92,0.96$ and 0.97 in the $0.49,0.67$ and $0.865 \mu \mathrm{m}$ spectral bands, respectively.

Finally, we applied the algorithm to the thickest parts of the plume by selecting all the pixels associated with AOTs larger than 0.4 (see the AOT map in Fig. 2). For less than half of the pixels, our algorithm successively reproduces the angular and spectral behavior of the total and polarized radiances and the results remain rather similar to the ones previously described. For the other pixels, our algorithm clearly fails to reproduce the angular properties of the total radiance. As an indication, the algorithm then retrieves nonspherical coarse mode particles associated with rather large absorption properties (SSA 0.92) and high values of AOT $(1<$ AOT < 4). We recall that the POLDER cloud mask algorithm initially rejects these data, and that cloud contamination is therefore likely to be possible (i.e., liquid or ice clouds). These results suggest that the core of the plume mainly consists of a mixture of absorbing volcanic dust and cloud particles. Ice clouds may be present within the plume since volcanic ash nucleates ice particles. This hypothesis is in agreement with results reported by Kahn et al. (2012) who detected patchy cirrus clouds within the same plume and for the same day, using the data provided by the Multi-
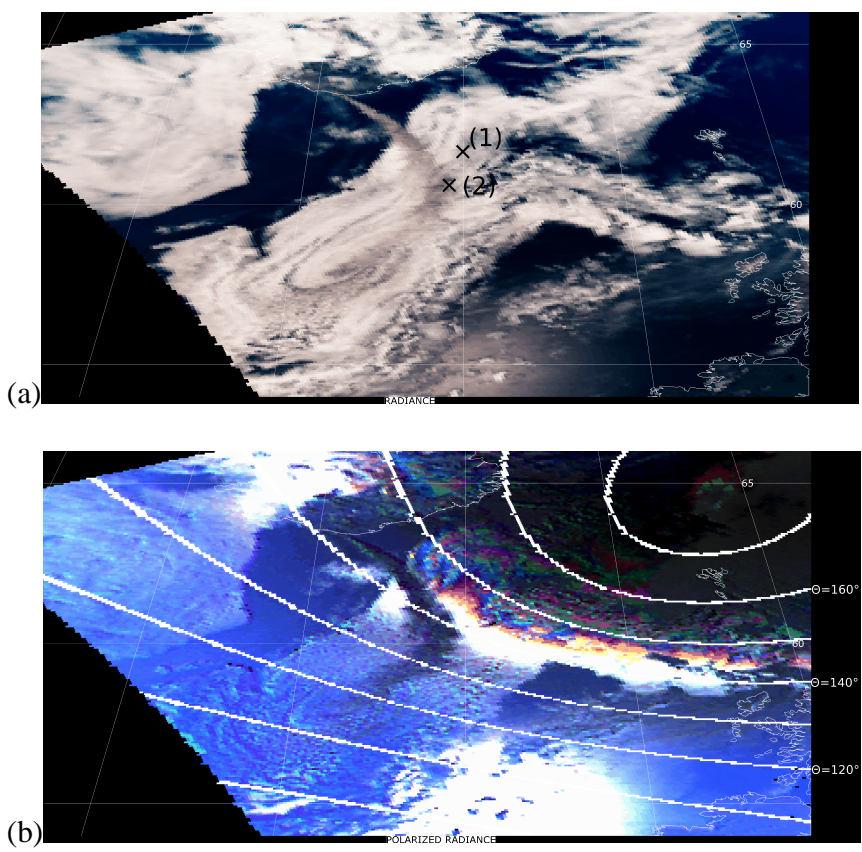

Fig. 5. RGB composites of POLDER measurements (a) in total radiance and (b) in polarized radiances. These images were produced using a combination of the POLDER spectral bands centered on $0.490 \mu \mathrm{m}, 0.670 \mu \mathrm{m}$ and $0.865 \mu \mathrm{m}$. These measurements are relative to the PARASOL overpass on 8 May 2010. The polarized radiances measured over the regions (1) and (2), indicated by crosses in (a), are shown in Fig. 6a. The aerosol properties retrieved over region (2) are reported in Table 2. In (b), the white circular lines are iso curves (lines of equal value) of scattering angles.

angle Imaging Spectro-Radiometer (MISR) instrument. The low value of the real part of the refractive index generally found in our retrievals might also be due to the presence of ice crystals in the plume or to the presence of liquid water coating the dust particles. Further interpretations and more comparisons are given in Sect. 4.

\subsection{Aerosols above cloud-deck}

\subsubsection{Case studies and observations}

Figure 5a shows a white-gray ash plume clearly visible over both cloud-free ocean scenes and cloud-covered scenes. We selected two areas labeled (1) and (2) that correspond to cloudy areas without and with aerosols above the cloud top, respectively. These areas are indicated by crosses in Fig. 5a. When located above clouds, the ash plume reduces the brightness of the scene. For instance, the total radiances at $0.865 \mu \mathrm{m}$ measured over the cloudy area with aerosols (2) decreases by a factor of about 1.5 in comparison with the ones measured over the cloudy area without aerosols (1). Figure $5 \mathrm{~b}$ shows the POLDER image in polarization. In Fig. 5b, the intense polarized signal observed at the bottom of the image corresponds to the Sun glint. Other high 


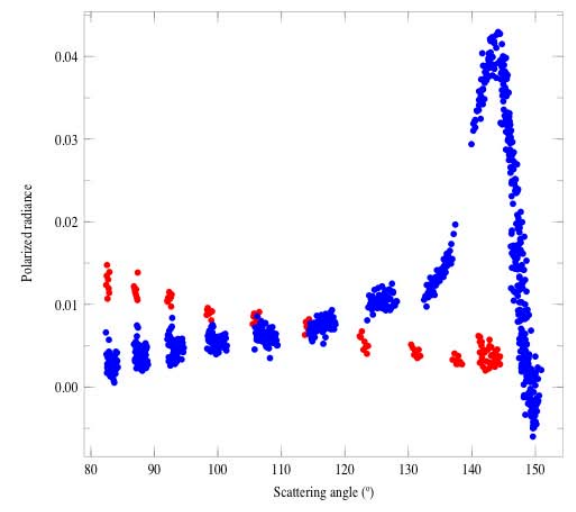

(a)

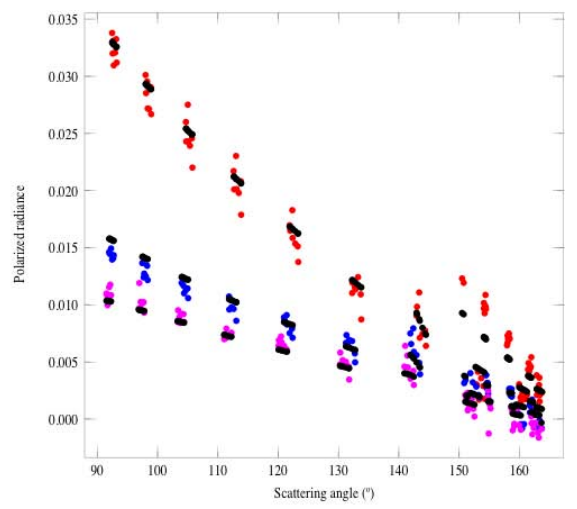

(b)

Fig. 6. (a)Polarized radiances measured by POLDER at $0.865 \mu \mathrm{m}$ as a function of the scattering angle for the regions (1) and (2) shown in Fig. 5a. Blue symbols represent the radiances relative to the region (1) where only low-clouds are present; red symbols represent the data of region (2) where the ash plume was detected above the clouds. (b)Polarized radiances measured over the ash plume on 6 May 2010 in function of the scattering angle at $0.49 \mu \mathrm{m}$ (red symbols), $0.67 \mu \mathrm{m}$ (blue symbols) and $0.865 \mu \mathrm{m}$ (magenta symbols) and simulated polarized radiances (black symbols).

levels of polarization are observed in the area of scattering angle close to $140^{\circ}$, which corresponds to cloud bows generated by spherical liquid water cloud droplets. The ash plume can easily be detected in the cloud bow region. As shown in Fig. 5b, the cloud bow is strongly attenuated and this attenuation is almost spectrally neutral, making the plume appear dark. This observation confirms that the ash plume contains a large amount of coarse particles, since those particles are typically associated with a rather flat spectral AOT.

The blue curve in Fig. 6a shows the typical polarized signature of a liquid cloud. We observe small levels of polarization at side-scattering angles $\left(80-130^{\circ}\right)$ and a strong peak of polarization around $140^{\circ}$ corresponding to the cloud bow. The red curve in Fig. 6a shows the ash plume polarized signature when it is observed above liquid clouds. The signature closely resembles those typically measured in cirrus clouds (Baran and Labonnote, 2007). The polarized radiance reaches small levels $(\approx 0.01)$ at forward scattering angles and progressively decreases with the scattering angle increasing. The aerosol layer is optically thick enough to entirely extinguish the polarized rainbow generated by the cloud underneath, which is an unprecedented observation. When the ash plume is optically thinner, we observe an attenuated cloud-bow and the levels of polarized radiance observed at side-scattering angles are smaller than 0.01 at $0.865 \mu \mathrm{m}$ (not shown).

The presence of aerosols above the cloud perturbs the retrieval of the cloud properties from passive remote sensing. Here, we report biases observed on the cloud top height, the cloud effective radius and the cloud phase. The cloud effective radius is retrieved from MODIS (Platnik et al., 2003). The cloud top altitude is derived using POLDER measurements acquired in the oxygen A-band (Vanbauce et al., 2003). The cloud phase is estimated by using an algo- rithm that combines the POLDER and MODIS measurements (Riedi et al., 2010). The cloud droplets effective radius is smaller in regions with aerosols above the clouds than in regions without aerosols above the clouds. When the plume is optically thick, as in region (2), the discrepancies can reach up to $10 \mu \mathrm{m}$, which is not surprising given the high aerosol loading. A cloud top height value of about $3.5 \mathrm{~km}$ is found over the ash plume in region (2), whereas the surrounding unperturbed clouds are associated with cloud top height values lower than $0.5 \mathrm{~km}$. The response of the cloud phase algorithm is also affected by the presence of the ash plume. The algorithm shows an unknown phase for several pixels. We also observed pixels associated with mixed phase (i.e., mixture of water and iced particles) and ice phase. An atypical radiative signature in polarization and strong effect in thermal infrared of the ash plume are probably responsible for the uncertainties observed in the cloud phase. The observed biases decrease progressively as the ash plume moves toward south of Iceland and becomes thinner.

The POLDER composite image in total radiances obtained on 6 May 2010 is shown in Fig. 8. The cloud cover is important around Iceland and the aerosol plume is blowing southeast of the island over cloud free and cloudy ocean scenes. The lidar CALIOP overpassed the ash plume far away from the source between latitudes $56^{\circ}$ and $59^{\circ}$. The lidar overpass track trace is shown in Fig. 9. The ash plume was located between 4 and $5 \mathrm{~km}$ over the ocean $\left(58.7^{\circ}<\right.$ latitude $\left.<59.7^{\circ}\right)$ and between 3.5 and $4.5 \mathrm{~km}$ above clouds $\left(57.2^{\circ}<\right.$ latitude $\left.<58.6^{\circ}\right)$. The cloud top altitude was about $1 \mathrm{~km}$. An interesting parameter provided by the lidar CALIOP is the depolarization ratio (DR) measured at $0.532 \mu \mathrm{m}$. It gives an indication of the shape of the particles. This quantity is estimated to be around $40 \%$ for the atmospheric layer where the ash plume was detected. A maximum 
value of $25 \%$ is generally reported for the DR in the case of mineral dust, whereas the DR for ice particles typically varies between 30 and $50 \%$ (Okamoto et al., 2010). The DR also depends on the particle size; the lidar measurements suggest that the volcanic ash particles could be larger in size than typical mineral dust particles or that some ice particles could be present in the volcanic plume.

\subsubsection{Volcanic aerosol properties above clouds}

Waquet et al. (2013) showed that the polarized measurements provided by POLDER are not sufficient to retrieve a detailed model of the aerosol microphysical properties for AAC (aerosol above cloud) scenes. The number of retrieved parameters must be reduced. We assume a value of $100 \%$ of non-spherical particles and an imaginary aerosol refractive index of 0.005 because it is coherent with the POLDER retrievals made over the fresh plume for cloud-free ocean scenes. We include the size parameters for the two modes, the real refractive index and the aerosol layer altitude in the retrieval scheme; otherwise it would not have been possible to fit the angular POLDER data. We did not report these microphysical parameters since they are uncertain. In Table 2, we reported the AOT, the Ångström parameter and the cloud droplets effective radius retrieved with the OEM algorithm for different cloudy regions covered by the ash plume. We also reported the scattering angle range sampled by POLDER $(\Theta)$.

The AOT retrieved over the core of the plume on 8 April is highly uncertain. The reason for this is that the cloud bow is fully extinguished and the sensitivity to the AOT is lost. It means that our method can only retrieve AOTs ranging between 0 and a maximum AOT around 2.5. This also explains why the droplet effective radius cannot be retrieved for this case since the volcanic plume entirely masks the cloud layer signal. According to our retrieval error results for cases 3 and 4 , we retrieve the AOT above clouds with an error inferior to $20 \%$ for AOT values ranging between 0.4 and 2.35. The retrieved Ångström exponents for cases 3 and 4 confirm that the aerosol size distribution is dominated by the coarse mode. Figure $6 \mathrm{~b}$ shows an example of the polarized radiances measured and modeled over the core of the ash plume. Our retrieved aerosol model allows to robustly reproduce the polarized radiances provided by POLDER. We replaced the mineral dust model included in the operational algorithm developed for the treatment of AAC scenes (Waquet et al., 2013) with a volcanic aerosol model. We noted that the volcanic aerosol model polarized less than the mineral dust model defined in Waquet et al. (2013) and it is associated with a smaller Ångström exponent.

In Fig. 7, we reported the AOT retrieved by POLDER on 8 May above both cloudy and cloud-free ocean pixels. This is a combination of the AOT retrieved with both the operational algorithm for cloud-free scenes (Herman et al., 2005) and the method previously described for cloudy scenes. The
Table 2. Aerosol and cloud parameters retrieved on 8 May 2010 and 6 May 2010 for different cloudy regions covered by the ash plume and the absolute retrieval uncertainties in brackets. The region (1) on 8 May is indicated in Fig. 5a. The regions (3) and (4) on 6 May are indicated by crosses in Fig. 8 .

\begin{tabular}{lllll}
\hline & $\begin{array}{l}\text { AOT } \\
(\text { at } 0.865 \mu \mathrm{m})\end{array}$ & $\begin{array}{l}\text { Angström } \\
\text { exponent }\end{array}$ & $\begin{array}{l}r_{\text {eff_cld }}(\mu \mathrm{m}) \\
\Theta\end{array}$ & $\begin{array}{l}\Theta \\
\left({ }^{\circ}\right)\end{array}$ \\
\hline$(2)$ & 4.2 & 0.2 & 6.0 & $80-145$ \\
0805 & $(2.7)$ & $(0.5)$ & $(10)$ & \\
\hline$(3)$ & 2.4 & -0.1 & 12.9 & $80-165$ \\
0605 & $(0.4)$ & $(1.2)$ & $(5.5)$ & \\
\hline$(4)$ & 0.48 & -0.11 & 15.1 & $90-160$ \\
0605 & $(0.05)$ & $(0.55)$ & $(0.3)$ & \\
\hline
\end{tabular}

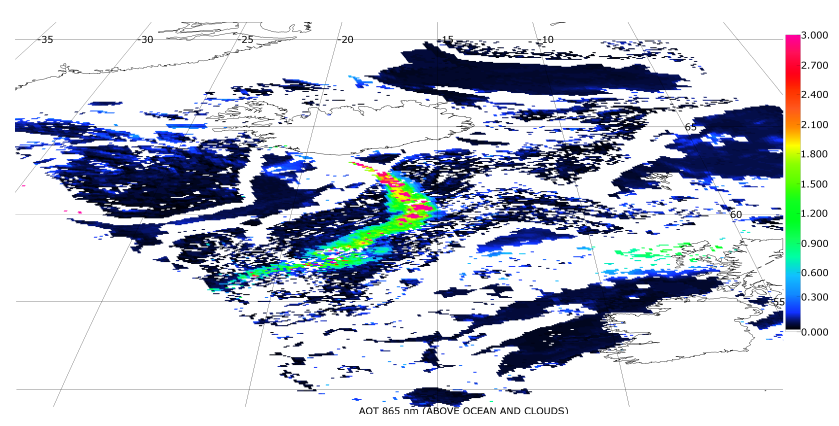

Fig. 7. Aerosol optical thickness retrieved at $0.865 \mu \mathrm{m}$ by POLDER over both ocean cloud-free pixels and cloudy pixels. The AOT values are relative to the PARASOL overpass on 8 May 2010.

aerosol model retrieved over region 2 (see Table 2) is used to constrain the retrieval of the AOT above clouds. We retrieved AOT values above clouds varying between 0 and 3 , suggesting that AOTs larger than 3 are expected above clouds since our method saturates for larger (AOT) values. The AOT above clouds progressively decreases as the plume moves south. Over the ocean, the Angström exponent is close to 0 , which indicates particles that are predominant in the coarse mode. A significant amount of aerosols is also detected in the northeast of the United Kingdom, over the ocean. These particles are predominant in the coarse mode, suggesting that they also originated from the eruption.

The AOTs retrieved above cloud-free and cloudy scenes on 6 May are reported in Fig. 9. The AOT retrieved above clouds is constrained using the aerosol model defined over region 3 (see Table 2). The RGB image shown in Fig. 7 allows the identification of cloudy and cloud-free pixels. The ash plume was first blowing east of Iceland, then over the Atlantic Ocean in the southeast direction. The AOTs above clouds are patchier than previously observed, but we note a good consistency between the AOTs retrieved above clearsky ocean and clouds. Other multilayer structures are also detected by our algorithm in the north and northeastern parts of Iceland (latitudes $>65^{\circ}$ ); they correspond to cirrus clouds 


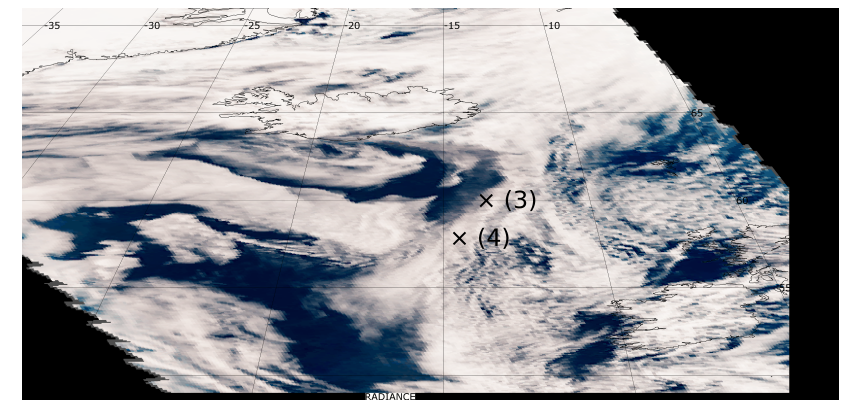

Fig. 8. RGB composites of POLDER measurements in total radiance. The total radiance values are relative to the PARASOL overpass on 6 May 2010. The aerosol properties retrieved over region (3) and (4) are reported in Table 2.

above liquid cloud scenes. As it was shown previously, the signatures of cirrus clouds and volcanic ash are rather similar in polarization and our method cannot distinguish between the two types of particles. This hypothesis was confirmed by using the brightness temperature difference (BTD) between the 11 and $12 \mu \mathrm{m}$ MODIS bands BTD B1-12, which $_{11}$ has shown an ability to distinguish dust from cirrus clouds (Zhang et al., 2006; Hansell et al., 2007). These structures observed in the north of Iceland were associated with positive $\mathrm{BTD}_{11-12}$ values, indicating clouds, whereas the structures located south of Iceland were associated with negative values ( $\mathrm{BTD}_{11-12} T<-2$ in the core of the plume), as expected for dust particles.

\section{Discussion}

Schumann et al. (2011) performed in situ measurements for different plume conditions acquiring two near-source samples for an aged plume (on 17 May 2010) and a fresh plume (on 2 May 2010). The analysis of the particle chemical composition showed that coarse mode particles for the aged volcanic plume mainly contained pure silicates, whereas coarse mode particles for the fresh volcanic plume consisted of a combination of pure silicates with "mixed" particles (i.e., silicates with small ammonium sulfate particles on their surface). These observations might explain why low real refractive index values are retrieved for the near-source plume. The low real refractive index of 1.42 could be also a result of an average between the refractive indexes of various particles, e.g., pure volcanic and sulfate aerosols or their mixtures. This might be also due to presence of liquid water coating the dust particles as a result of water vapor condensation near the emission point (Delmelle et al., 2005; Lathem et al., 2011). This would be consistent with the presence of spherical particles near the emission point ( $\mathrm{FS} \sim 25 \%$ ), which would tend to disappear as the plume is transported and liquid water evaporates or turns into ice crystals.

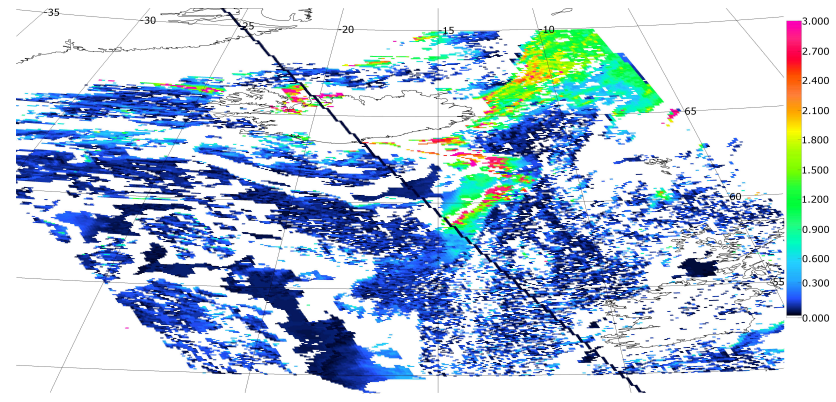

Fig. 9. Optical thickness retrieved at $0.865 \mu \mathrm{m}$ by POLDER over both ocean cloud-free pixels and cloudy pixels and lidar CALIOP trace (black line). The AOT values are relative to the PARASOL overpass on 6 May 2010.

Our approach fails to reproduce the angular behavior of the total radiance measurements for a large number of pixels acquired over the core of the near-source plume. We believe it is because we did not include cirrus cloud models in our algorithm. Kahn et al. (2012) investigated the same event with the MISR instrument and found cirrus clouds in the volcanic plume. To reproduce the MISR total radiance measurements acquired over the core of the near-source plume, Kahn et al. (2012) had to use a combination of various fine mode particle models, non-spherical theoretical dust models (i.e., dust grains) and cirrus cloud models. Let us mention that, except for the core of the plume, we generally have a good agreement between the two instruments retrievals. They both detect non-spherical coarse mode particles and observe the same trends for the Ångström exponent as a function of the plume type (fresh or aged) or as a function of the distance to the plume. They both found significant absorption over the near-source plume on 7 May although the MISR algorithm generally found larger absorption.

Properties of a downwind volcanic plume observed over Lille on 17 April 2010 were analyzed in detail using groundbased measurements (Derimian et al., 2012). In this study, the AERONET, lidar, and broadband flux observations in conjunction with numerical simulations were used to assess the volcanic aerosol optical properties. For the coarse mode of the volcanic plume, they found an effective radius of $1.28 \mu \mathrm{m}$, a real part of the refractive index of $1.51( \pm 0.05)$ with an imaginary part of $0.008( \pm 0.002)$ at $0.870 \mu \mathrm{m}$ and a SSA of about $0.92( \pm 0.02)$ at $0.870 \mu \mathrm{m}$, which drops down to $0.81( \pm 0.02)$ at $0.44 \mu \mathrm{m}$. An increased real refractive index during the eruption time was also found in a study by Mortier et al. (2013). Some retrievals made for the downwind case on 16 April (one day before the above-mentioned observations) also indicate high real refractive index values at some pixels; however, the retrievals do not show the same large absorption for this case. There are several possible explanations for these results. For instance, lower absorption properties and higher SSA values (SSA of 0.97) were reported for an aged volcanic plume observed over France on 19 April 2010 (Hervo 
et al., 2012), suggesting some variability in the ash absorption. It is also possible that our estimate of the ocean albedo biased our retrievals of the SSA since both parameters cannot be independently retrieved using our present approach. New methods performing a simultaneous retrieval of surface reflectance and aerosol properties (Hasekamp et al., 2011; Duvovik et al., 2011) can overcome this present shortcoming.

\section{Summary and conclusions}

Total and polarized radiances provided by the Polarization and Directionality of Earth Reflectances (POLDER) satellite sensor are used to retrieve the microphysical and optical properties of the volcanic plume observed during the Eyjafjallajökull eruption in April-May 2010 over the ocean for both cloud-free and cloudy scenes. We selected two plume conditions, fresh aerosols near the sources (three cases) and a downwind volcanic plume observed over the North Sea $30 \mathrm{~h}$ after its injection into the atmosphere (aged aerosols). We presented retrievals and examined assumptions and a priori information employed in our inversion scheme. Namely, for the ocean surface, a Lambertian reflectance is assumed to estimate the contribution of the water leaving radiance. The directional variation and the polarization contribution of water leaving radiance were evaluated and considered as additional sources of error. The ocean albedo was estimated using the MODIS ocean color products and a mean value computed over three months was used. For the aerosol microphysics, a bi-modal size distribution was assumed. Both modes were expected to follow a lognormal law with the same complex refractive index. Some assumptions were used to constrain the spectral dependence of the complex refractive index. Finally, spheroid models were considered to describe the optical and scattering properties of the volcanic dust aerosols and we used a combination of spheroid models retrieved for mineral dust particles by Dubovik et al. (2006). Although it was developed for dust, the model enabled accurate reproduction of the spectral and angular variability of the observed radiances in most cases.

Over the cloud-free areas, it was possible to retrieve the detailed microphysical properties of the aerosols, using polarized and total radiance measurements provided by POLDER in combination with an optimal method estimation (OEM) algorithm. Over the fresh plume on 7 May 2010, aerosols were mainly non-spherical with an effective radius equal to $1.75( \pm 0.35) \mu \mathrm{m}$ and an Ångström exponent (AE) close to 0.0 . The retrieved real refractive $(\mathrm{RR})$ index in the vicinity of the plume was rather low $(1.38<\mathrm{RR}<1.48)$, which was not expected. Far from the fresh plume (distance $>150 \mathrm{~km}$ ), in addition to the coarse mode, there were particles retrieved in the accumulation mode suggesting a mixture of sulfate aerosols and volcanic dust, resulting in an $\mathrm{AE}$ around 0.8. The downwind aged plume was associated with an Ångström exponent of around 0.4. Non-spherical coarse particles as well as some fine mode particles were also detected within this plume. We found significant absorption properties over some parts of the near-source plume. The presence of ice crystals was expected within the core of the fresh plume and a significant concentration of sulfur dioxide was detected over the fresh plume by the OMI satellite instrument.

For aerosol above clouds (AAC) scenes, the retrieval method was restricted to polarized measurements and optically thick liquid clouds, since the retrieval of the aerosol properties was not affected by the brightness of the clouds (i.e., cloud albedo). For AAC scenes, we primarily mapped the aerosol optical thickness (AOT) of the volcanic plume above clouds and estimated the associated Ångström exponent. The retrieval of the aerosol properties performed above clouds confirmed low Ångström exponent values for nearsource plumes. The AOT retrieved above clouds and clearsky ocean scenes were generally consistent, confirming the robustness of the method. Our results obtained for AAC scenes with volcanic dust allowed us to study extreme AAC events (with AOT as large as 3). We found that there is an upper limit for the retrieval of the AOT above clouds with polarized measurements, which is around $2.5( \pm 0.5)$ at $0.865 \mu \mathrm{m}$, depending on the aerosol model and also on the droplets effective radius of the below cloud layer. We found that all the cloud parameters retrieved by passive sensors were not surprisingly biased due to the presence of the elevated volcanic plumes. Our results also indicate that it is possible to retrieve the optical thickness of optically thin cirrus layers present above liquid clouds with polarized passive measurements, which is interesting in the context of multilayer cloud detection. Our results suggest that thermal infrared measurements can be used for a qualitative detection of the type of particles (i.e., dust or cirrus clouds), whereas polarized measurements can be used to accurately derive the optical thickness of the lofted cirrus layer.

Acknowledgements. This work has been supported by the Programme National de Télédétection Spatiale (PNTS, http://www.insu.cnrs.fr/actions-sur-projets/ pnts-programme-national-de-teledetection-spatiale), grant no. PNTS-2013-10.

Edited by: C. Bay Hasager

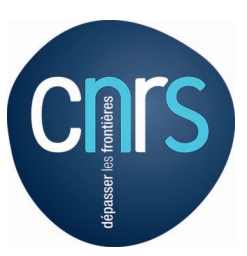

The publication of this article is financed by CNRS-INSU. 


\section{References}

Baran, A. J. and C.-Labonnote, L.: A self-consistent scattering model for cirrus. I: The solar region, Quant. J. Royal Meteorol. Soc., 133, 1899-1912, 2007.

Chami, M., Santer, R., and Dilligeard, E.: Radiative transfer model for the computation of radiance and polarization in an oceanatmosphere system: Polarization properties of suspended matter for remote sensing, Appl. Opt., 40, 2398-2416, 2001.

Delmelle, P., Villiéras, F., and Pelletier M.: Surface area, porosity and water adsorption properties of fine volcanic ash particles, Bull. Volcanol., 67, 160-169, 2005.

Derimian, Y., Dubovik, O. Tanre, D., Goloub, P., Lapyonok, T., and Mortier, A.: Optical properties and radiative forcing of the Eyjafjallajökull volcanic ash layer observed over Lille, France, in 2010, J. Geophys. Res., 117, D00U25, doi:10.1029/2011JD016815, 2012.

Dubovik, O., Holben, B. N., Eck, F. T., Smirnov, A., Kaufman, J. Y., King, D. M., Tanré, D., and Slutsker, I.: Variability of absorption and optical properties of key aerosol types observed in worldwide locations, J. Atmos. Sci., 59, 590-608, 2002.

Dubovik, O., Sinyuk, A., Lapyonok, T., Holben, B. N., Mishchenko, M., Yang, P., Eck, T. F., Volten, H., Muñoz, O., Veihelmann, B., van der Zande, W.J., Leon, J.-F., Sorokin, M., and Slutsker, I.: Application of spheroid models to account for aerosol particle nonsphericity in remote sensing of desert dust, J. Geophys. Res., 111, D11208, doi:10.1029/2005JD006619, 2006.

Dubovik, O., Herman, M., Holdak, A., Lapyonok, T., Tanré, D., Deuzé, J. L., Ducos, F., Sinyuk, A., and Lopatin, A.: Statistically optimized inversion algorithm for enhanced retrieval of aerosol properties from spectral multi-angle polarimetric satellite observations, Atmos. Meas. Tech., 4, 975-1018, doi:10.5194/amt-4975-2011, 2011.

Fougnie, B., Bracco, G., Lafrance, B., Ruffel, C., Hagolle, O., and Tinel, C.: PARASOL inflight calibration and performance, Appl. Opt., 46, 5435-5451, 2007.

Gassó, S.: Satelite observations of the impact of weak volcanic activity on marine clouds, J. Geophys. Res., 113, D14S19, doi:10.1029/2007JD009106, 2008.

Graf, H. F., Langmann, B., and Feichter, J.: The contribution of Earth degassing to the atmospheric sulfur budget, Chem. Geol., 147, 131-145, 1998.

Hansell, R. a., Ou, S. C., Liou K. N., Roskovensky, J. K., Tsay, S. C., Hsu, C., and Ji, Q.: Simultaneous detection/separation of mineral dust and cirrus clouds using MODIS thermal infrared window data, Geophys. Res. Lett., 34, 1-5, doi:10.1029/2007GL029388, 2007.

Harmel, T. and Chami, M.: Invariance of polarized reflectance measured at the top of atmosphere by PARASOL satellite instrument in the visible range with marine constituents in open ocean waters, Opt. Express, 16, 6064-6080, 2008.

Hasekamp, O., Litvinov, P., and Butz, A.: Aerosol properties over the ocean from PARASOL multiangle photopolarimetric measurements, J. Geophys. Res., 116, D14204, doi:10.1029/2010JD015469, 2011.

Haywood, J. M., Osborne, S. R., and Abel, S. J.: The effect of overlying absorbing aerosol layers on remote sensing retrievals of cloud effective radius and cloud optical depth, Q. J. Roy. Meteorol. Soc., 130, 779-800, doi:10.1256/qj.03.100, 2004.
Herman, M., Deuzé, J. L., Marchand, A., Roger, B., and Lallart, P.: Aerosol remote sensing from POLDER/ADEOS over the ocean: Improved retrieval using a nonspherical particle model, J. Geophys. Res., 110, D10S02, doi:10.1029/2004JD004798, 2005.

Hervo, M., Quennehen, B., Kristiansen, N. I., Boulon, J., Stohl, A., Fréville, P., Pichon, J.-M., Picard, D., Labazuy, P., Gouhier, M., Roger, J.-C., Colomb, A., Schwarzenboeck, A., and Sellegri, K.: Physical and optical properties of 2010 Eyjafjallajökull volcanic eruption aerosol: ground-based, Lidar and airborne measurements in France, Atmos. Chem. Phys., 12, 17211736, doi:10.5194/acp-12-1721-2012, 2012.

Kahn, R. A. and Limbacher, J.: Eyjafjallajökull volcano plume particle-type characterization from space-based multi-angle imaging, Atmos. Chem. Phys., 12, 9459-9477, doi:10.5194/acp12-9459-2012, 2012.

Lathem, T. L., Kumar, P., Nenes, A., Dufek, J., Sokolik, I. N., Trail, M. and, Russell, A.: Hygroscopic properties of volcanic ash, Geophys. Res. Lett., 38, L11802, doi:10.1029/2011GL047298, 2011.

Lenoble, J., Herman, M., Deuzé, J. L, Lafrance, B., Santer, R., and Tanré, D.: A successive order of scattering code for solving the vector equation of transfer in the earths atmosphere with aerosols, J. Quant. Spectrosc. Ra., 107, 479-507, doi:10.1016/j.jqsrt.2007.03.010, 2007.

Mather, T. A., Pyle, D. M., and Oppenheimer, C.: Tropospheric Volcanic Aerosol, Geophysical Monograph, 139, 189-212, 2003.

Mishchenko, M. I. and Travis, L. D.: T-matrix computations of light scattering by large spheroidal particles, Opt. Commun., 109, 1621, 1994

Mortier, A., Goloub, P., Podvin, T., Deroo, C., Chaikovsky, A., Ajtai, N., Blarel, L., Tanre, D., and Derimian, Y.: Detection and characterization of volcanic ash plumes over Lille during the Eyjafjallajökull eruption, Atmos. Chem. Phys., 13, 3705-3720, doi:10.5194/acp-13-3705-2013, 2013.

Muñoz O., Volten, H., Hovenier, J. W., Veihelmann, B., van der Zande, W. J., Waters, L. B. F. M., and Rose, W. I.: Scattering matrices of volcanic ash particles of Mount St. Helens, Redoubt, and Mount Spurr Volcanoes, J. Geophys. Res., 109, D16201, doi:10.1029/2004JD004684, 2004.

Okamoto, H., Kumaoka, N., Nishizawa, T., Sugimoto N., and Hagihara, Y.: Calibration of $1064 \mathrm{~nm}$ channel and retrieval of aerosol extinction from CALIOP, 25th International Laser Radar Conference, 2010

Platnick, S., King, M. D., Ackerman, S. A., Menzel, W. P., Baum, B. A. Riédi, J. C., and Frey, R. A.: The MODIS Cloud Products: Algorithms and Examples From Terra, IEEE T. Geosci. Remote, 41, 459-473, 2003.

Riedi, J., Marchant, B., Platnick, S., Baum, B. A., Thieuleux, F., Oudard, C., Parol, F., Nicolas, J.-M., and Dubuisson, P.: Cloud thermodynamic phase inferred from merged POLDER and MODIS data, Atmos. Chem. Phys., 10, 11851-11865, doi:10.5194/acp-10-11851-2010, 2010.

Schumann, U., Weinzierl, B., Reitebuch, O., Schlager, H., Minikin, A., Forster, C., Baumann, R., Sailer, T., Graf, K., Mannstein, H., Voigt, C., Rahm, S., Simmet, R., Scheibe, M., Lichtenstern, M., Stock, P., Rüba, H., Schäuble, D., Tafferner, A., Rautenhaus, M., Gerz, T., Ziereis, H., Krautstrunk, M., Mallaun, C., Gayet, J.F., Lieke, K., Kandler, K., Ebert, M., Weinbruch, S., Stohl, A., Gasteiger, J., Groß, S., Freudenthaler, V., Wiegner, M., Ansmann, 
A., Tesche, M., Olafsson, H., and Sturm, K.: Airborne observations of the Eyjafjalla volcano ash cloud over Europe during air space closure in April and May 2010, Atmos. Chem. Phys., 11, 2245-2279, doi:10.5194/acp-11-2245-2011, 2011.

Scollo, S., Kahn, R. A., Nelson, D. L., Coltelli, M., Diner, D. J., Garay, M. J., and Realmuto, V. J.: MISR observations of Etna volcanic plumes, J. Geophys. Res., 117, D06210, doi:10.1029/2011JD016625, 2012.

Tanré, D., Bréon, F. M., Deuzé, J. L., Dubovik, O., Ducos, F., François, P., Goloub, P., Herman, M., Lifermann, A., and Waquet, F.: Remote sensing of aerosols by using polarized, directional and spectral measurements within the A-Train: the PARASOL mission, Atmos. Meas. Tech., 4, 1383-1395, doi:10.5194/amt-4-1383-2011, 2011.

Vanbauce, C., Cadet, B., and Marchand, R. T.: Comparison of POLDER apparent and corrected oxygen pressure to ARM/MMCR cloud boundary pressures, Geophys. Res. Lett., 30, 16.1-16.4, doi:10.1029/2002GL016449, 2003.

Volten, H., Munoz, O., Rol, E., de Haan, J. F., Vassen, W., Hovenier, J. W., Muinonen, K., and Nousiainen, T.: Scattering matrices of mineral aerosol particles at $441.6 \mathrm{~nm}$ and $632.8 \mathrm{~nm}$, J. Geophys. Res., 106, 17375-17401, 2001.
Waquet, F., Riedi, J., Labonnote, L. C., Goloub, P., Cairns, B., Deuzé, J.-L., and Tanré, D.: Aerosol remote sensing over clouds using the A-Train observations, J. Atmos. Sci., 66, 2468-2480, doi:10.1175/2009JAS3026.1, 2009a.

Waquet, F., Cairns, B., Knobelspiesse, K., Chowdhary, J. Travis, L. D., Schmid, B., and Mishchenko, M. I.:. Polarimetric remote sensing of aerosols over land, J. Geophys. Res., 114, D01206, doi:10.1029/2008JD010619, 2009b.

Waquet, F., Cornet, C., Deuzé, J.-L., Dubovik, O., Ducos, F., Goloub, P., Herman, M., Lapyonok, T., Labonnote, L. C., Riedi, J., Tanré, D., Thieuleux, F., and Vanbauce, C.: Retrieval of aerosol microphysical and optical properties above liquid clouds from POLDER/PARASOL polarization measurements, Atmos. Meas. Tech., 6, 991-1016, doi:10.5194/amt-6-991-2013, 2013.

Williams, H., Turner, F. J., and Gilbert, C. M.: Petrography, W. H. Freeman, New York, 1982.

Zhang, P., Lu, N., Hu, X., and Dong, C.: Identification and physical retrieval of dust storm using three MODIS thermal IR channels, Global Planet. Change, 52, 197-206, doi:10.1016/j.gloplacha.2006.02.014, 2006. 